\title{
Invitro Study of Thrombolytic Activity by Using Aqueous Preparation of Different Parts of Carica Papaya Plant Extract
}

\author{
Kalaiyarasi.L ${ }^{1}$, Mubeen sultana. $D^{2}$ \\ ${ }^{I}(P G \&$ Research Department of Zoology, JBAS college for Women/University of Madras, India) \\ ${ }^{2}(P G \&$ Research Department of Zoology, JBAS college for Women/ University of Madras, India)
}

\begin{abstract}
The objective of this present study was to investigate the thrombolytic activity of aqueous extract of Carica papaya plant (root, seed and leaf) parts. Streptokinase was used as a positive control. The human blood was taken as test sample. The mean \% of clot lysis for streptokinase was $36.44 \%$. Similarly, the root, seed and leaf extracts of Carica papaya showed the mean \% of clot lysis as $24.70 \%, 24.29 \%$ and $23.67 \%$ respectively. When all this three extracts were compared with streptokinase, they were significant at $p<0.05 \%$.

Keywords: aqueous extract, carica papaya, control, streptokinase, thrombolytic activity.
\end{abstract}

\section{Introduction}

Thrombosis is the formation of a blood clot inside a blood vessel, obstructing the flow of blood through the circulatory system. Usually the blood clotting arises from a complex interaction of various mechanisms, including the activation of the coagulation, fibrinolytic systems, disruption of the vascular endothelium, and the generalized activation of the cellular mechanisms resulting in clotting on the surface of monocytes and platelets in circulation [1]. Platelets are essential in the maintenance of cardiovascular integrity and in the control of bleeding through forming blood clot. However, they are also implicated in the pathological progression of atherosclerotic lesions and arterial vascular thrombosis [2]. Uncontrolled platelet aggregation is critical in arterial thrombosis and may cause life threatening disorders [3]. Thromboembolic disorders such as pulmonary emboli, deep vein thrombosis, strokes and heart attacks are the main causes of morbidity and mortality in developed countries [4].

Thrombolytics are used to dissolve the fibrin of blood clots which are potentially life-threatening, especially those in the arteries of the heart and lungs. It is also used against the clots formed in shunts during kidney dialysis and multiple pulmonary emboli. Therefore, thrombolytics or antithrombotic agents are considered as a key tool in the treatment and/or prevention of cardiovascular thrombotic diseases. Commonly used thrombolytic agents are alteplase, antistreplase, streptokinase, urokinase and tissue plasminogen activator (tPA) to dissolve clots.

For more than five decades, anticoagulant drugs consisting of heparins, vitamin $\mathrm{K}$ antagonists, and their derivatives have been the major players in the clinical setting. Although it is well established that aspirin is one of the antithrombotic agent which still provides an effective secondary prevention of ischemic cardiovascular disorders, this drug can produce hemorrhagic events and upper gastrointestinal bleeding as major drawbacks [5]. During the past decade, several trials have led to an effort in the search for novel compounds or sources to suppress the platelet aggregation [6,7].

Similarly, all available thrombolytic agents still have significant shortcomings, including the need for large doses to be maximally effective, limited fibrin specificity and bleeding tendency. Because of the shortcomings of the available thrombolytic drugs, attempts are underway to develop improved recombinant variants of these drugs [8-12]. Throughout history, plants have been used as a major medicinal source, with interest in herbal formulations increasing globally over the past decade. In addition, extracts of natural products provide a useful source of bioactive compounds which can be developed as drugs directly or provide novel structural templates. Today, large proportion of drugs in clinical use are produced by the synthesis of natural products and/or their derivatives, and new plant- derived medicines are continually being discovered [13-15]. For this reason the leaves and/or twigs, stem, bark and underground parts of plants are most often used for traditional medicines. Primary bioassay screens are important for the initial screening of plants for bioactive chemical constituents and are often the first step in drug development. The active compounds in medicinal plants often vary in different parts of the plant, with the whole plant seldom being in medicine.

\subsection{Carica papaya}

The papaya or papaw is the fruit of the plant Carica papaya, the sole species in the genus Carica of the plant family Caricaceae. The papaya is a large, tree-like plant, with a single stem growing from 5 to $10 \mathrm{~m}$ tall, with spirally arranged leaves confined to the top of the trunk. The lower trunk is conspicuously scarred where leaves and fruits were borne. The leaves are large, $50-70 \mathrm{~cm}$ in diameter, deeply palmately lobed, with seven 
lobes. Unusually for such large plants, the trees are dioecious. The tree is usually unbranched, unless lopped. The flowers are similar in shape to the flowers of the plumeria, but are much smaller and wax-like. They appear on the axils of the leaves, maturing into large fruit $15-45 \mathrm{~cm}$ long and $10-30 \mathrm{~cm}$ in diameter. Carica papaya is an evergreen shrub or small tree that grows best in full sun to light shade. It is widely grown now and used in different parts of the world not only for food but also for ornamental purpose.

Papaya leaf has a number of benefits. Recent research on papaya leaf tea extract has demonstrated cancer cell growth inhibition. It appears to boost the production of key signalling molecules called Th1-type cytokines, which help regulate the immune system. Papaya leaves contain various phytoconstituents like saponins, tannins, cardiac glycosides and alkaloids. The alkaloids present include carpaine, pseudocarpaine and dehydrocarpaine I and II. These constituents can act on the bone marrow, prevent its destruction and enhance its ability to produce platelets. Moreover, it can also prevent platelet destruction in the blood and thereby increase the life of the platelet in circulation. Papaya leaf when dried and cured like a cigar is smoked by asthmatic persons. An infusion of fresh papaya leaves is used by person to expel or destroy intestinal worms. Fresh young papaya is also used as a remedy for colic pain a certain stomach disorder or cramp.

The black seeds of the papaya are edible and have a sharp, spicy taste. Papaya seeds have antibacterial, anti-helminthic and anti-amoebic properties and are effective against E.coli, Salmonella and Staphylococcus infections. Seeds may protect the kidneys from toxin induced kidney failure. It can eliminate intestinal parasites, detoxify the liver and cure piles and typhoid. In wistar rats nephro-protective activity was observed in dose related manner. Concentration of urine and creatinine were evaluated. Dried papaya seeds actually look quite similar to pepper corns and can be used in just the same. Oral administration of Carica papaya seed extract could induce reversible male infertility and could be used for pharmaceutical development of a male contraceptive. The contraceptive efficacy of the seeds of Carica papaya has been earlier demonstrated in rats, mice and rabbits $[16,17]$. Juice from papaya roots is used in some countries of Asia to ease urinary troubles. A decoction formed by boiling the outer part of the roots of the papaya tree in the cure of dyspepsia.

Papaya is a powerhouse of nutrients and is available throughout the year. It is a rich source of three powerful antioxidant vitamin $\mathrm{C}$, vitamin $\mathrm{A}$ and vitamin $\mathrm{E}$; the minerals, magnesium, iron, calcium and potassium; the B vitamin pantothenic acid, folate and fiber. In addition to all this, it contains a digestive enzyme-papain which effectively treats the causes of trauma, allergies and sports injuries.

\subsection{Uses and pharmacology}

Carica papaya has a wide range of pharmacological effects, including antiseptic, antimicrobial, antiparasitic, anti-inflammatory, antihypertensive, diuretic, antihyperlipidemic, antidiabetic, and contraceptive activity. While limited data exists for most of these effects, there is some evidence for its use in healing decubitus ulcers and other wounds and for treating intestinal worms in humans.

\subsubsection{Antimicrobial activity}

Papaya may exert a proteolytic effect on bacteria resulting from the production of a coagulum that immobilizes microorganisms and protects the host against bacterial infections [18]. In addition, papaya may improve the efficiency of phagocytic cells that destroy bacteria [19]. Papaya also contains the alkaloid, carpaine, which has antibacterial properties [20].

In laboratory tests, extracts from skin, flesh, and seeds of both ripe and unripe papaya showed in vitro antibacterial activity against several microorganisms, including Bacillus cereus, Bacillus subtilis, Enterobacter cloacae, Escherichia coli, Klebsiella pneumonia, Proteus vulgaris, Pseudomonas aeruginosa, Salmonella typhi, Shigella flexneri and Staphylococcus aureus [21].

\subsubsection{Anti-Inflammatory Activity}

Papain has been used to control oedema and inflammation associated with surgical or accidental trauma. Papain solutions have produced therapeutic effects in Patients with inflammatory disorders of the genitals, intestine, liver and eye [22]. The leaves of papaya have been used for the treatment of inflammatory conditions such as asthma, rheumatism, arthritis and wound healing. However, there have been few studies investigating the biological activity of the dried leaves, which are used traditionally for the treatment of inflammatory conditions [23].

\subsubsection{Antiulcer Activity}

A study revealed the antiulcer potential of aqueous and methanolic extracts of unripe papaya fruit in experimental rat models. The extracts reduced the ulcer index; the methanolic extract demonstrated better protection against indomethacin-induced ulcers, the ethanol extract against ethanol-induced gastric ulcers. The cytoprotective and antimotility properties may account for the antiulcer properties of unripe fruit [24]. 


\subsubsection{Diuretic Activity}

Diuretic activity is associated with the aqueous extracts of Carica papaya. Adult male Sprague Dawley rats were given an oral dose of $10 \mathrm{mg} / \mathrm{kg}$ of Carica papaya root extracts. The demonstrated increased urine output $(\mathrm{p}<0.01)$ was similar to receiving hydrochlorothiazide $10 \mathrm{mg} / \mathrm{kg}[25]$.

\subsubsection{Antidiabetic Activity}

A recent survey of traditional medical practitioners, herbalists, and herb sellers in selected local government areas in Lagos State in Nigeria identified Carica papaya as a popular traditional antidiabetic herbal remedy [26]. A recent study revealed that papaya is an intermediate glycemic index food [27].

\subsubsection{Antioxidant Activity}

Papaya contains antioxidant components such as vitamin C, malic acid, and citric acid; a limited number of studies have examined the antioxidant potential of papaya. In a study of Wistar rats, the rats were divided into a control group or 1 of 4 treatment groups. The treatment groups received 100, 200, or 400 $\mathrm{mg} / \mathrm{kg} / \mathrm{day}$ of Carica papaya juice or vitamin E (alpha-tocopherol). The study demonstrated that the antioxidative stress potential of the juice was comparable with alpha-tocopherol [28].

\subsubsection{Antihypertensive Activity}

Antihypertensive activity is associated with ethanolic extracts from the unriped fruit of Carica papaya. Both hydralazine (200 mcg per 100g intravenously [IV] and Carica papaya extract (20mg/kg IV) produced a depression in mean arterial pressure in renal hypertensive, DOCA-salt hypertensive and normotensive rats. The papaya extract decreased mean arterial pressure $28 \%$ more than hydralazine in the hypertensive groups. The papaya extract produced relaxation of vascular tone that was attenuated by phentolamine. It was concluded that the fruit of Carica papaya probably contains antihypertensive agent(s) that exhibit mainly alpha-adrenoceptor activity [29].

\subsubsection{Antihyperlipidemic Activity}

The raw fruit of Carica papaya displayed potential as an antihyperlipidemic agent in Sprague-Dawley rats with hyperlipidemia induced by IV injection of triton WR1339 or a high-fat diet. The fresh juice of Carica papaya exerted a lowering of serum cholesterol and triglycerides within the first 24 hours in the triton model. Similarly, the aqueous and methanolic extracts of Carica papaya markedly reduced the levels after 7 days of repeated oral treatment when compared with the control (atorvastatin and fenofibrate-treated) group [30].

\subsubsection{Anthelmintic Activity}

Carica papaya contains proven anthelmintic chemical agents such as benzyl isothiocyanate and papain. However, papain is unstable in the presence of digestive juices, which may account for its lack of efficacy as an anthelminthic drug in clinical studies [31]. Benzyl isothiocyanate is therefore considered to be the chief or sole anthelminthic drug in papaya seed extracts [32]. Various studies in animals confirm the effectiveness of Carica papaya seeds as an anthelmintic effective drug against nematodes found in animals [33].

\subsubsection{Other antiparasitic/antiprotozoal activity}

Carica papaya has documented activity against protozoa in addition to intestinal parasites in animal models. These include antiamebic, antitrichomonal, antimalarial, and leishmanicidal properties.

\subsubsection{Toxicology Test}

An acute toxicity test (median lethal dose) in adult male Wistar rats demonstrated that papaya juice (from the ripe fruit) was not lethal and no sign of toxicity was observed in rats receiving up to and including doses as high as $1,500 \mathrm{mg} / \mathrm{kg}$ after oral administration. Thus, papaya juice is considered nontoxic. Oral administration of aqueous and methanolic extracts of whole, unripe Carica papaya fruit of up to $5,000 \mathrm{mg} / \mathrm{kg}$ in mice did not produce lethality or signs of acute toxicity after 24 hours. Papaya seed extract may exert potentially toxic effects on mammalian vascular smooth muscle. Benzyl isothiocyanate, the chief bioactive ingredient in seeds, irreversibly inhibits the contraction of dog carotid artery. Papaya extract, when present in high concentration, was found to be cytotoxic by increasing the membrane permeability to calcium [34].

Our study was mainly focused to check whether this Carica papaya plant has thrombolytic activity or not. Because it shows many more activities useful for human health along with it is a blood purifier which was scientifically proven. That is why our aim is to evaluate the mean percentage of clot lysis in blood sample using the extract. 


\subsection{Blood sample}

\section{Materials And Methods}

Whole blood $(3 \mathrm{ml})$ was drawn from healthy human volunteers $(\mathrm{n}=10)$ without a history of oral contraceptive or anticoagulant therapy. From which $500 \mu \mathrm{l}(0.5 \mathrm{ml})$ of blood was transferred to each of the previously weighed micro centrifuge tubes to form clots.

\subsection{Carica papaya}

The samples (Carica papaya roots, leaves and seeds) were collected from in and around Urappakkam, Kancheepuram district, Tamilnadu, India.

\subsection{Streptokinase (SK)}

Commercially available lyophilized Stukinase (Streptokinase) vial (Samarth pharmaceutical Ltd.) of 15, 00,000 I.U., was collected and 5ml sterile distilled water was added and mixed properly. This suspension was used as a stock from which $100 \mu \mathrm{l}$ (30,000 I.U.) was used for in vitro thrombolysis [35].

\subsection{Procedure for clot lysis}

$3 \mathrm{ml}$ venous blood drawn from healthy volunteers and was distributed in five different labelled, pre weighed sterile micro centrifuge tube $(0.5 \mathrm{ml} /$ tube $)$ and incubated at $37^{\circ} \mathrm{C}$ for 45 minutes [35]. After clot formation, serum was completely removed without disturbing the clot using micro pipette and each tube having clot was again weighed to determine the total clot weight of every individual (clot weight $=$ weight of clot containing tube - weight of tube alone).

To first micro centrifuge tube containing pre weighed clot, $100 \mu 1$ of leaf extract of Carica papaya was added. Similarly, to the second micro centrifuge tube, $100 \mu 1$ of root extract of papaya plant was added. To third micro centrifuge containing blood clot, $100 \mu \mathrm{l}$ of seed extract of papaya was added individually. As a positive thrombolytic control, $100 \mu \mathrm{l}$ of streptokinase was added to the control tube numbered.

All the tubes were then incubated at $37^{\circ} \mathrm{C}$ for 90 minutes and observed for clot lysis. After incubation, fluid released was removed and tubes were again weighed to observe the difference in weight after clot disruption. Difference obtained in weight taken before and after clot lysis was expressed as percentage of clot lysis. The thrombolytic activities of all extracts were evaluated. The experiment was repeated 10 times with the blood samples of 10 volunteers. Results were tabulated.

\subsection{Preparation of aqueous extract of Carica papaya}

Fresh different parts of Carica papaya plants were collected and washed properly with distilled water. The plants were divided into root, seed and leaf sections, were shade dried at room temperature for 15 days. Dried parts were uniformly grinded using mechanical grinder. The dried powder of plant material was extracted in distilled water.

Ten gram of ground plant material was soaked in $100 \mathrm{ml}$ of distilled water in a round bottom flask and loaded in the heating mantle at a temperature of $65-70^{\circ} \mathrm{C}$ for 15 minutes for boiling following the method of Kumar et al (2010). After $15 \mathrm{~min}$ reduces the temperature to $30-40^{\circ} \mathrm{C}$ and allowed it for 1 hour. Then the mixture was filtered using whatmann filter paper number 1 . Thus each ground papaya plant materials were extracted separately. The dried extracts were weighed and stored in air tight container with necessary markings for identification and kept in refrigerator $\left(0-4^{\circ} \mathrm{C}\right)$ for future investigation.

\subsection{Thrombolytic activity of streptokinase}

\section{Results}

Addition of $100 \mu \mathrm{l}$ of streptokinase as a positive control (30,000 I.U.) to the preweighed blood clots along with 90 minutes incubation at $37^{\circ} \mathrm{C}$ showed $36.44 \%$ clot lysis (Table 2, Fig.1).

\subsection{Thrombolytic activity of Carica papaya}

But when $100 \mu$ l of Carica papaya aqueous preparation of root extract was added to 10 different blood clots, it showed $24.70 \%$ (Table 2, Fig.1). The correlation difference between streptokinase and root is -0.099 and it is significant at $<0.05 \%$ (Table 3). Similarly, when $100 \mu 1$ of Carica papaya aqueous preparation of seed extract was added to 10 different blood clots, it showed a thrombolytic activity of $24.29 \%$ (Table 2, Fig.1). The correlation difference between streptokinase and seed is 0.456 and it is significant at $<0.05 \%$ (Table 3 ).

However, when $100 \mu 1$ of Carica papaya aqueous preparation of leaf extract was added to the blood clots, significant thrombolytic activity of $23.67 \%$ was obtained (Table 2, Fig.1).The correlation difference between streptokinase and leaf is 0.647 and it is significant at $<0.05 \%$ (Table 3 ).

Among all the different extracts, the aqueous preparation of Carica papaya root extract showed maximum thrombolytic activity. So, the correlation difference between papaya root and seed is 0.545 and it is significant at 
$<0.05 \%$ (Table 3). The correlation difference between papaya root and leaf is 0.226 and it is significant at $<0.05 \%$ (Table 3 ).

TABLE 1: Effects of different extracts on dissolution of blood

Clots of ten individuals blood sample

\begin{tabular}{|c|c|c|c|c|c|c|c|c|c|c|}
\hline SAMPLE & A & B & C & D & E & F & G & H & I & J \\
\hline Streptokinase & $20.2 \%$ & $65.5 \%$ & $25.3 \%$ & $35.7 \%$ & $31.1 \%$ & $34.6 \%$ & $39.5 \%$ & $34.3 \%$ & $38.4 \%$ & $39.8 \%$ \\
\hline Papaya root & $10.4 \%$ & $10.4 \%$ & $7.9 \%$ & $43.4 \%$ & $46.9 \%$ & $18.5 \%$ & $19.9 \%$ & $35.4 \%$ & $35.1 \%$ & $19.1 \%$ \\
\hline Papaya seed & $12.4 \%$ & $27.7 \%$ & $8.2 \%$ & $32.2 \%$ & $20.7 \%$ & $28.6 \%$ & $22.9 \%$ & $27.9 \%$ & $42.6 \%$ & $19.7 \%$ \\
\hline Papaya leaf & $15.5 \%$ & $39.7 \%$ & $6.2 \%$ & $32.3 \%$ & $19.3 \%$ & $30.9 \%$ & $14.9 \%$ & $35.0 \%$ & $18.6 \%$ & $24.3 \%$ \\
\hline
\end{tabular}

TABLE 2: Thrombolytic activity of different samples in terms

Of Mean \pm S.D $(n=10)$

\begin{tabular}{|c|c|}
\hline SAMPLE & MEAN \pm STANDARD DEVIATION \\
\hline Streptokinase & $36.44 \pm 11.99$ \\
\hline Papaya root & $24.70 \pm 14.33$ \\
\hline Papaya seed & $24.29 \pm 9.87$ \\
\hline Papaya leaf & $23.67 \pm 10.57$ \\
\hline
\end{tabular}

TABLE 3: Paired sample correlation

\begin{tabular}{|c|c|c|}
\hline SAMPLE & CORRELATION & SIGNIFICANCE \\
\hline Streptokinase \& papaya root extract & -0.099 & $*$ \\
\hline Streptokinase \& papaya seed extract & 0.456 & $*$ \\
\hline Streptokinase \&papaya leaf extract & 0.647 & $*$ \\
\hline Papaya root and papaya seed extract & 0.545 & $*$ \\
\hline Papaya root and papaya leaf extract & 0.226 & $*$ \\
\hline
\end{tabular}

Values Represent Mean \pm SD

*Represent significant at $<0.05 \%$ level

Since each parts of Carica papaya possesses different thrombolytic activity in different ranges, it can be considered as a whole mass for thrombolysis.

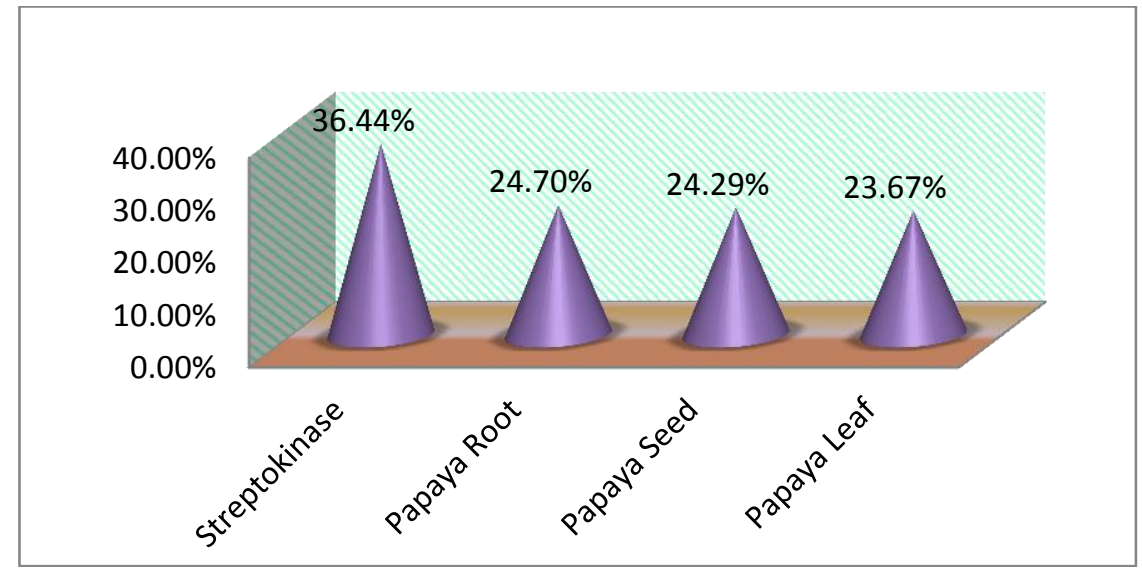

Figure 1: Thrombolytic activity of different samples

\subsection{Statistical analysis}

To verify the results obtained the statistical analysis of the thrombolytic effect of the three samples of the plant products were carried out and the data obtained is represented as mean \pm standard deviation. The statistical analysis that was used is paired t-test method. In this, each samples correlation were analysed.

\section{Conclusion}

The extracts of all the three parts of Carica papaya can be used to design anti thrombotic agent due to its moderate thrombolytic activity. Further work is needed to isolate the bioactive components or secondary metabolites and study thoroughly for more precise and accurate activities. But this in vitro study demonstrated that folk medicine can be as effective as modern medicine without the side effects of modern medicine. We can use herbal preparation of plant extracts effectively instead of using chemically prepared thrombolytic drugs to avoid threatened side effects. 


\section{References}

[1] FR. Rickles, A. Falanga, Molecular basis for the relationship between thrombosis and cancer, Thromb Res, 102, 2001, 215-224

[2] A.E. May, P. Seizer, and M. Gawaz, "Platelets: inflammatory firebugs of vascular walls, "Arteriosclerosis, Thrombosis, and Vascular Biology, 28(3), 2008, s5-s10.

[3] M.J. Davies and A.C.Thomas, "Plaque fissuring - the cause of acute myocardial infarction, sudden ischemic death, and crescendo angina," British Heart Journal, 53(4), 1985, 363-373.

[4] G. Dickneite, D. Seiffe, KH. Diehl, M. Rogers, J. Czech, Pharmacological characterization on a new 4-amidinophenyl-alanine thrombin-inhibitor (CRC220), Thromb Res, 77, 1995, 357-368.

[5] S. Johnson, "Known knowns and known unknowns: risks associated with combination antithrombotic therapy," Thrombosis Research, 123(1), 2008, S7-S11.

[6] A.J.Lau, D.F Toh, T.K. Chua, Y.K. Pang, S.O. Woo, and H.L. Koh, "Antiplatelet and anticoagulant effects of Panax notoginseng: comparison of raw and steamed Panax not ginseng with Panax ginseng and Panax quinquefolium," Journal of Ethno pharmacology, 125(3), 2009, 380-386.

[7] K.H. Ryu, H.Y. Han, S.Y. Lee, "Ginkgo biloba extract enhances antiplatelet and antithrombotic effects of cilostazol without prolongation of bleeding time," Thrombosis Research, 124(3), 2009, 328-334.

[8] FA. Nicolini, WW. Nichols, JL. Mehta, TG. Saldeen, R. Schofield, M. Ross, DW. Player, GB. Pohl, C. Mattsson, Sustained reflow in dogs with coronary thrombosis with K2P, a novel mutant of tissue plasminogen activator. J Am Coll Cardiol, 20, 1992, $228-235$.

[9] DS. Adams, LA. Griffin, WR. Nachajko, VB. Reddy, CM. Wei, A synthetic DNA encoding a modified human urokinase resistant to inhibition by serum plasminogen activator inhibitor. J Biol Chem, 266, 1991, 8476-8482.

[10] HR. Lijnen, B. Vanhoef, F. De-Cock, K. Okada, S. Ueshima, O. Matsuo, On the mechanism of fibrin-specific plasminogen activation by staphylokinase. J Biol Chem, 266, 1991. 11826-32.

[11] VJ. Marder, Recombinant streptokinase-opportunity for an improved agent. Blood Coagul Marder VJ, 1993.

[12] DH. Wu, GY. Shi, WJ. Chuang, JM. Hsu, KC. Young, CW. Chang, Coiled coil region of streptokinase gamma-domain is essential for plasminogen activation. J Biol Chem, 276, 2001, 15025-15033.

[13] BE. Van Wyk, B. Van Oudtshoorn, N. Gericke, Medicinal plants of South Africa, Briza, Pretoria, 1997,pp 8, 12, 14, 20.

[14] JMR. De Medeiros, M. Macedo, JP. Contancia, C. Nguyen, G. Cunningham, DH. Miles, Antithrombin activity of medicinal plants of the Azores, JEthnopharmacol, 72, 2000, 157-165.

[15] A. Rahman, MI. Choudhary, WJ. Thomsen, Bioassay techniques for drug development, Harwood Academic Publishers, Singapore, 2001, 1-3.

[16] RP. Das, Effect of papaya seed on the genital organ and fertility of male rats, Indian J EXP Biol, 18, 1980, 408-409.

[17] FV. Udoh, PB. Udoh, EE. Umoh, Activity of alkaloid extract of Carica papaya seeds on reproductive functions in male Wistar rats, Pharm Biol, 43, 2005, 563-567.

[18] SJ. Wimalawansa, Papaya in the treatment of chronic infected ulcers, Ceylon Med J, 26(3), 1981, $129-132$.

[19] S. Gurung, N. Skalko-Basnet, Wound healing properties of Carica papaya latex: in vivo evaluation in mice burn model. J Ethnopharmacol, 121(2), 2009, 338-341.

[20] H. Hewitt, Y. Wint, L. Talabere, The use of papaya on pressure ulcers, Am J Nurs, 102(12), 2002, 73-77.

[21] JA. Osato, LA. Santiago, GM. Remo, MS. Cuadra, A. Mori, Antimicrobial and antioxidant activities of unripe papaya, Life Sci, 53(17), 1993, 1383-1389.

[22] MR. Rakhimov, Pharmacological study of papain from the papaya plant cultivated in Uzbekistan [in Russian], Eksp Klin Farmakol, 63(3), 2000, 55-57.

[23] BV. Owoyele, OM. Adebukola, AA. Funmilayo, AO. Soladoye, Anti-inflammatory activities of ethanolic extract of Carica papaya leaves, Inflammopharmacology, 16(4), 2008, 168-173.

[24] AC. Ezike, PA. Akah, CO. Okoli, NA. Ezeuchenne, S. Ezeugwu, Carica papaya (paw paw) unripe fruit may be beneficial in ulcer, J Med Food, 12(6), 2009, 1268-1273.

[25] B. Sripanidkulchai, V. Wongpanich, P. Laupattarakasem, J. Suwansaksri, D. Jirakulsomchok, Diuretic effects of selected Thai indigenous medicinal plants in rats, J Ethnopharmacol, 75(2-3), 2001, 185-190.

[26] AA. Gbolade, Inventory of antidiabetic plants in selected districts of Lagos State, Nigeria, J Ethnopharmacol, 121(1), 2009, 135139.

[27] SD. Robert, AA. Ismail, T. Winn, TM. Wolever, Glycemic index of common Malaysian fruits, Asia Pac J Clin Nutr, 17(1), 2008, 35-39.

[28] S. Mehdipour, N .Yasa, G. Dehghan, Antioxidant potentials of Iranian Carica papaya juice in vitro and in vivo are comparable to alpha-tocopherol, Phytother Res, 20(7), 2006, 591-594.

[29] AE. Eno, OI. Owo, EH. Itam, RS. Konya, Blood pressure depression by the fruit juice of Carica papaya (L.) in renal and DOCAinduced hypertension in the rat, Phytother Res, 14(4), 2000, 235-239.

[30] A. Banerjee, R. Vaghasiya, N. Shrivastava, H. Podn, M. Nivsarkas, Anti-hyperlipidemic effect of Carica papaya L. in Sprague dawley rats, Niger J Nat Prod Med, 10, 2006, 69-72.

[31] S. Foster, VE. Tyler, Tyler's Honest Herbal: A Sensible Guide to the Use of Herbs and Related Remedies, 4th ed, Binghamton, NY: Haworth Herbal Press, 1999.

[32] AJ. Barrett, DJ. Buttle, Names and numbers of papaya proteinases, Biochem J, 228(2), 1985,527.

[33] JM. Burke, A. Wells, P. Casey, JE. Miller, Garlic and papaya lack control over gastrointestinal nematodes in goats and lambs, Vet Parasitol, 159, 2009, 171-174.

[34] RK. Wilson, TK. Kwan, CY. Kwan, GJ. Sorger, Effects of papaya seed extract and benzyl isothiocyanate on vascular contraction, Life Sci, 71(5), 2002, 497-507.

[35] S. Prasad, RS. Kashyap, JY. Deopujari, HJ. Purohit, GM. Taori, HF. Daginawala, Effect of Fagonia Arabica (Dhamasa) on in vitro thrombolysis, BMC Compl Altern Med,7(36), 2007.

[36] G. Kumar, L. Karthik and KVB. Rao, Antibacterial activity of aqueous extracts of Calotropis gigantea leaves - An in vitro study, Intern J Pharm Sci Review, 4(2), 2010, 141-144. 